\title{
“RIEN DE CE QUI EST HUMAIN EST ÉTRANGER" : A ETNOGRAFIA DE MICHEL LEIRIS A PARTIR DA REVISTA FRANCESA DOCUMENTS (1929-1930)
}

\author{
“RIEN DE CE QUI EST HUMAIN EST ÉTRANGER" : MICHEL \\ LEIRIS'S ETHNOGRAPHY THROUGH FRENCH MAGAZINE \\ DOCUMENTS (1929-1930)
}

\author{
Gabriela Theophilo \\ Doutoranda em história - UFRJ \\ E-mail: gabitheophilo@gmail.com
}

\begin{abstract}
RESUMO: Entre os anos de 1929 e de 1930 o escritor e etnólogo francês Michel Leiris (1901-1990) colaborou para revista de etnografia Documents. Nas páginas do periódico foram veiculados alguns dos principais debates das artes e da etnologia francesa no período. Tratava-se de um momento conturbado no continente europeu e de muitos questionamentos no que dizia respeito às concepções oitocentistas de "civilização". Pode-se dizer que a revista funcionou como um "laboratório" no qual o escritor Georges Bataille (diretor do periódico) e Michel Leiris puderam propor e testar novas formas de se pensar a sociedade ocidental e suas relações com outras sociedades. As contribuições deste para a revista foram profundamente marcadas por suas leituras acerca do gnosticismo, do neoplatonismo e do hermetismo - que ele mesmo costumava denominar apenas como "ocultismo" ou "misticismo". Este artigo visa, portanto, empreender uma leitura pormenorizada de artigos escritos por Leiris em Documents, procurando investigar de que modos os debates ali travados contribuíram para suas reflexões posteriores no âmbito da disciplina etnográfica e no da chamada "escrita de si".
\end{abstract}

PALAVRAS-CHAVE: etnografia, literatura, mística

ABSTRACT: In between the years of 1929 and 1930, the French writer and ethnologist Michel Leiris (19011990) wrote for the ethnography magazine "Documents". At that time, the magazine published some of the main debates on French arts and ethnography. It was a contrived time for Europe, posing many questions about the concept of "civilization" inherited from the eighteenth century thinkers. One might say that the magazine was some kind of "laboratory" where the writer Georges Bataille ("Documents" magazine editor) and Michel Leiris were able to propose and test new frameworks on how to think the western society and its relationship with other societies. Leiris articles were deeply shaped by his study of Gnosticism, Neo-Platonism and Hermeticism - but he would only categorize his thinking as "occultism" or "mysticism". This paper intends to engage on a detailed reading of Michel Leiris texts published on Documents magazine, trying to figure out how its intellectual debates were influential on his reflections on ethnology and the so-called "writing of the self".

KEY-WORDS: ethnography, literature, mystique

Oficina do Historiador, Porto Alegre, EDIPUCRS, v. 7, n. 2, jul./dez. 2014, p. 140-154. 
A obra de Michel Leiris - composta, principalmente, de estudos etnográficos relativos a sociedades africanas e de livros considerados "autoetnográficos" - ${ }^{1}$ é extremamente profícua para o debate de inúmeras questões prementes no âmbito das ciências humanas. Ela pode ser colocada entre aquelas que partiram de premissas já presentes em vertentes do movimento romântico para exercerem críticas à modernidade, ao cientificismo e ao racionalismo ocidentais, questionando, por exemplo, a neutralidade das relações entre sujeito e objeto do conhecimento e abrindo caminhos para os desenvolvimentos ulteriores do conjunto de argumentos que constituiriam a chamada "crítica pós-moderna". ${ }^{2}$

Antes de tornar-se etnólogo profissional, Leiris escreveu poesia e envolveu-se, entre os anos de 1924 e de 1929, nas discussões do grupo surrealista francês - que se configurou em torno das premissas político-literárias estabelecidas por André Breton. Em 1929, entretanto, ele se afastou de Breton e se reaproximou de seu amigo Georges Bataille, formado pela École des Chartes e, à época, escritor e funcionário da Biblioteca Nacional da França. Neste ano, Bataille fora convidado para ser diretor da revista de arqueologia, belas artes e etnografia, Documents (posteriormente denominada revista de arqueologia, belas artes, etnografia e variedades), que circulou em Paris entre abril de 1929 e abril de 1931, em quinze números. Tanto os debates surrealistas, quanto aqueles empreendidos em Documents - que se colocou como concorrente de La Révolution Surréaliste - marcariam profundamente suas reflexões etnográficas e sua obra literária em torno da escrita de si.

Documents foi criada por Georges Wildenstein, Pierre D’Espezel, Georges-Henry Rivière e Carl Einstein como uma revista científica ${ }^{3}$, voltada, principalmente, para o estudo de objetos arqueológicos, das chamadas Belas Artes em geral e da dita "arte primitiva", num momento em que o Estado e os museus franceses tinham acesso privilegiado a objetos africanos (advindos de suas colônias no continente), e que o mercado das artes em torno

\footnotetext{
${ }^{1}$ Leiris afirmaria inúmeras vezes ao longo da vida que só conseguia escrever literatura como confissão. Dentre os textos considerados autobiográficos ou autoetnográficos estão L'âge d'Homme e os quatro livros que compõe La règle du jeu (Biffures, Fourbis, Fibrilles, Frêle Bruit). Leiris também escreveu poesia, crítica de arte, textos sobre teatro e ópera, artigos sobre temas relacionados à etnografia e trabalhos acadêmicos de etnografia.

${ }^{2}$ Luiz Fernando Dias Duarte estudou os modos como diversas premissas românticas marcaram a constituição de problemas, objetos e métodos das ciências humanas - e da antropologia, em particular -, no Ocidente (DUARTE, 2004 e 2012).

${ }^{3}$ Georges Wildenstein (1892-1963), patrocinador do periódico, importante crítico, além de colecionador e marchand de arte e, à época, diretor da Gazette de Beaux-arts. Pierre D`Espezel, diretor da revista Aréthuse, serviu como intermediário entre o então escritor e bibliotecário Georges Bataille e Wildenstein. Georges HenriRivière (1897-1985), então subdiretor do Museu de Etnologia do Trocadéro; Carl Einstein (1885-1940), escritor, crítico e historiador da arte, que introduzira na Alemanha o cubismo e a arte africana.
}

Oficina do Historiador, Porto Alegre, EDIPUCRS, v. 7, n. 2, jul./dez. 2014, p. 140-154. 
desses objetos - impulsionado, também, pelas discussões da vanguarda surrealista - entrava em efervescência.

Entretanto, a direção de Bataille, sua contundente crítica anti-idealista ao surrealismo de Breton, e a posterior atração de diversos artistas e escritores "dissidentes" do surrealismo, confeririam um caráter considerado cada vez mais insólito à revista, afastando-a do projeto inicial de seus fundadores. ${ }^{4}$ De acordo com Michel Leiris (2008, p. 15) em texto sobre Georges Bataille e o periódico, a diversidade de temas, imagens e contribuições em Documents constituiriam "uma mistura impossível": "amálgama de disciplinas" - e de indisciplinas -, a revista se tornaria, por fim, uma "máquina de guerra contra ideias préconcebidas".

Autodefinida como "uma enciclopédia do século XX segundo métodos novos" (PEIXOTO, 2007, p. 26), pode-se dizer que o programa que foi, aos poucos, se esboçando na revista, visava, sim, à coleta e à exposição dos “documentos de seu tempo". Entretanto, em Documents, a exposição do ser humano e de seus documentos (principalmente através de objetos arqueológicos e etnológicos) tinha por objetivo revelar e colocar à mostra até mesmo as faces e formas (informes) mais monstruosas e violentas da existência humana. ${ }^{5}$

Bataille, de forma similar a André Breton, defendia uma arte e uma literatura que fossem capazes de provocar um deslocamento do pensamento. No entanto, esse deslocamento não se destinava a fazer surgir a centelha na qual sonho e realidade se converteriam numa realidade outra, como Breton afirmava nos manifestos do surrealismo. O deslocamento, para Bataille, deveria ter o significado de um desmentido violento. A "fulguração" para ele era, portanto, justamente esse desmentido, capaz de colocar o homem diante de sua única verdade, na medida do impossível, no limiar, no "inacabamento" permanente.

\footnotetext{
${ }^{4}$ Nesse artigo não será feita descrição ou análise mais aprofundada da revista Documents em seu conjunto, nem de sua posição no campo artístico e etnográfico francês à época, pois serão priorizados os debates empreendidos por Leiris. Para mais informações sobre a revista ver, por exemplo, Dennis Hollier (1992 p. 3-24) e Georges Didi-Huberman (1995). Sobre a revista Documents no contexto dos debates entre André Breton e Georges Bataille há um artigo meu (THEOPHILO, 2012), intitulado A revista de etnografia Documents e seu projeto documental-realista (1929-1930). Já sobre a relação do surrealismo com a arte dita primitiva, museus etnográficos e mercado das artes ver, por exemplo, Els Lagrou (2008) e Sally Price (2000).

${ }^{5}$ Os primeiros números de Documents vem acompanhados de um dicionário que não obedece à ordem alfabética e no qual são definidos alguns verbetes escolhidos pelos escritores. No verbete informe, Bataille escreve : " un dictionnaire commencerait à partir du moment où il ne donnerait plus le sens mais les besognes des mots. Ainsi informe n'est pas seulement un adjectif ayant tel sens mais un terme servant à déclasser, exigeant généralement que chaque chose ait sa forme (...) il faudrait, en effet, pour que les hommes académiques soient contents, que l'univers prenne forme (...) par contre affirmer que l'univers ne ressemble à rien et n'est qu'informe revient à dire que l'univers est quelque chose comme une araignée ou un crachat" (BATAILLE, 1929, p. 382).
}

Oficina do Historiador, Porto Alegre, EDIPUCRS, v. 7, n. 2, jul./dez. 2014, p. 140-154. 
Sendo assim, nas páginas de Documents, Bataille (1970, p. 180) preconizava um "baixo materialismo" que designasse "interpretação direta, excluindo todo o idealismo, de fenômenos brutos, e não um sistema fundado sobre elementos fragmentários de uma análise ideológica elaborada sob o signo de preceptivas religiosas”. Desse modo, recusava qualquer tipo de concepção que sobrepusesse o ideal à materialidade das coisas, já que a idealização da matéria nada mais seria do que uma ocultação de seu poder de desmentir as representações (idealizadas) que os homens construiriam de si mesmos e do mundo (MORAES, 2010, p. 200).

De acordo com Georges Didi-Huberman (1995), no livro La ressemblance informe, a disposição das imagens e dos textos na revista Documents colocava em jogo e em questão a noção judaico-cristã de semelhança. Criando um "regime centrífugo, móvel, de semelhanças", aproximando, colocando em contato e criando passagens e relações entre objetos e formas de diferentes estatutos, a revista, em seu conjunto, exercia uma forte crítica anti-idealista, recusando toda substância da imagem. A criação de semelhanças entre formas dessemelhantes, ou a contaminação de uma imagem por outra, respeitava um princípio dialético que não permitia, porém, sua solução numa síntese: era o privilégio das relações sobre os termos, a partir de um corpus documental aberto, não finalizado.

Os documentos humanos apresentados dessa forma, associados aos textos, decompunham a construção mítica judaico-cristã em torno da figura humana, ao transgredirem "as formas seculares do antropomorfismo", além de quebrarem as hierarquias entre "alto" e "baixo", virtuoso e vil, modelo e cópia. ${ }^{6}$ Tratava-se da construção de um "inventário arbitrário" do mundo, que se opunha a qualquer formulação totalizante, baseada na recusa de considerar o corpo humano como forma substancial, estável ou harmoniosa (DIDI-HUBERMAN, 1995, p. 9-163).

Desse modo, ainda segundo Didi-Huberman (1995, p. 82-83), Bataille fez uma escolha não filosófica - ou antifilosófica - porém, teórica, que residia num equilíbrio paradoxal entre Hegel e Nietzsche. A dialética das formas de Bataille não era, portanto, axiomática, lógica ou abstrata, mas apresentava uma força heurística. Nesse sentido, Documents daria uma "lição fenomenológica, ao conferir à moral, à fobia e ao tabu uma expressão sensorial afetiva". O

\footnotetext{
${ }^{6}$ A tentativa de quebra das hierarquias cultural e socialmente construídas lembrava o programa surrealista. Entretanto, enquanto Breton almejava um fim, almejava a quebra das hierarquias pela fusão, pela síntese, pelo alcance do "homem total", e ao fim e ao cabo, pela chegada a "um nível superior", Bataille almejava um desmentido permanente da imagem idealizada que o homem construíra de si mesmo, através de uma dialética sem síntese - da presença: era a "insubordinação dos fatos materiais".
}

Oficina do Historiador, Porto Alegre, EDIPUCRS, v. 7, n. 2, jul./dez. 2014, p. 140-154. 
"dualismo materialista" de Bataille tendia sempre ao dessemelhante, ao tout-autre, irredutível a qualquer representação homogeneizante (MORAES, 2005, p. 115-116).

Era, certamente, nesse sentido, que Bataille se diferenciava de Leiris, que, como se verá, buscava sempre a unidade e a semelhança a partir dos jogos de analogias e de correspondências entre todas as coisas. Leiris escreveu para Documents sobre os mais diversos temas: etnografia, arte, misticismo, erotismo, entre outros. Todavia, eles apresentavam coerência em torno de algumas de suas preocupações principais. Entre elas, estava a busca pelas formas profundamente humanas. Decifrar o humano, seus desejos mais secretos, era uma forma de descoberta da própria realidade em toda a sua crueza e com todas as suas contradições e, sobretudo, uma forma de descoberta de si mesmo em sua relação com o mundo.

O primeiro número de Documents, datado de abril de 1929, trazia, assim, um texto de Leiris (1929a, p. 48-52) intitulado "Notes sur deux figures microcosmiques des XIV e XV siècles", cujos argumentos centrais permitem dar conta, a posteriori, do sentido geral da sua contribuição para a revista, ao longo de sua existência. Nesse artigo, Leiris versava sobre duas imagens reproduzidas numa obra de Fritz Saxl sobre astrologia e mitologia, lançada em 1927. Tratava-se de imagens que representavam, nos termos de Leiris, o "microcosmo", o "pequeno mundo" ou o "homem" e suas relações com o "macrocosmo", o "grande mundo" ou o "universo".

Uma das imagens, do século XIV, mostrava o homem no centro de um círculo, tendo a Terra a seus pés, representada por uma flor. No desenho, os órgãos dos sentidos e as diversas zonas do corpo humano estavam ligados a diferentes partes do universo. Leiris explicava a imagem a partir da doutrina cabalística judaica: antes do pecado original, Adão constituía a imagem fiel de Adam Kadmon, seu protótipo no "pensamento divino". Seu corpo, quase imaterial, feito à imagem e semelhança de Deus, era indivisível. O primeiro pecado, porém, provocara o condensamento e a subdivisão desse corpo, dando origem à humanidade. $\mathrm{O}$ objetivo final da vida humana, assim, seguindo a interpretação de Leiris, seria o de reconstituir esse grande ser primitivo que a formava. De acordo com a cabala cristã, por sua vez, o homem reencontraria essa unidade ao final dos tempos, graças à intervenção divina.

Ainda segundo ele, essa teoria da origem do homem tornava compreensível o motivo pelo qual os representantes das chamadas ciências ocultas - que, como a cabala, seria uma mistura de ideias judaicas e cristãs conformadas pelo neoplatonismo - consideravam o

Oficina do Historiador, Porto Alegre, EDIPUCRS, v. 7, n. 2, jul./dez. 2014, p. 140-154. 
homem como correspondente ao universo, em todas as suas partes. O corpo humano era uma miniatura do universo, assim como a alma humana, uma miniatura de Deus. Os iniciados na cabala, portanto, teriam formulado a tese da natureza microcósmica do homem, exposta de maneira clara, ainda de acordo com Leiris, nos escritos de Paracelso:

O macrocosmo é composto de um céu e de uma terra postos em relação pelas trocas de germes e astros, de modo que o céu imprime e dirige o movimento, ao passo que a Terra o recebe e obedece. Quanto ao "microcosmo" ou "homem", feito à imagem de Deus e do macrocosmo - dos quais ele resume todas as forças e todas as propriedades -, ele tem também seu céu e sua Terra, seus astros e suas forças físicas correspondentes. O cérebro é o lugar do céu, princípio de seus pensamentos, de suas vontades, seus movimentos e seus sentimentos. O céu está em relação com os astros do universo, cuja influência se estende sobre seus pensamentos e seus atos ${ }^{7}$ (PARACELSO APUD LEIRIS, 1929a, p. 50).

A segunda imagem, por sua vez, originária de um tratado de astrologia do século $\mathrm{XV}$, mostrava um homem aprisionado no interior de uma estrutura circular, semelhante a uma grande teia de aranha, sob a influência dos sete planetas e das doze divisões do círculo zodiacal. As doze linhas que emanavam dos segmentos do círculo indicariam, assim, a parte do corpo correspondente a cada um dos signos do zodíaco.

De acordo com Leiris, então, quase por toda parte - não somente nas cabalas judaica e cristã, mas também entre os filósofos gregos e na maior parte das ciências ocultas -, era possível encontrar esse modo de identificação, verdadeiro sistema que partia do homem ao universo e, inversamente, do universo ao homem. Esse mecanismo responderia menos a motivos de ordem racional do que a uma vicissitude humana, a alguns dos desejos mais secretos e instintivos do homem, entre eles "o desejo do absoluto ou a busca do uno".

Mesmo as figuras simbólicas, animais ou humanas, atribuídas às constelações, seriam um vestígio do totemismo primitivo, como já haviam estabelecido, por um lado, Lévy-Bruhl, e, por outro, Freud. No mundo ocidental, o sistema que mais se aproximava da concepção de uma "mentalidade primitiva" era aquele das ciências ocultas: os sistemas de identificação por analogia representavam as forças instintivas do homem, de modo que muitos enigmas em

\footnotetext{
7“ Le macrocosme, écrit Paracelse, se compose d'une ciel et d'une terre mis en correspondance par le rapport des germes avec les astres, de manière que le ciel imprime et dirige le mouvement tandis que la Terre le reçoit et obéit. Quant au microcosme ou à l'homme, fait à l'image de Dieu et du macrocosme dont il résume en lui-même toutes les forces et toutes les propriétés, il a aussi son ciel et sa terre, ses astres et ses forces physiques correspondantes" (Tradução minha).
}

Oficina do Historiador, Porto Alegre, EDIPUCRS, v. 7, n. 2, jul./dez. 2014, p. 140-154. 
torno dos mais variados gestos e práticas humanos poderiam ser resolvidos, de acordo com Leiris (1929a, p. 52), se as ciências ocultas fossem consideradas como um espelho, refletindo essas grandes tendências.

O entendimento da realidade para Michel Leiris passava, então, pelo entendimento do homem e de seus instintos primeiros. Esses instintos, de acordo com os seus estudos, remetiam a relações de identificação com todas as coisas e à busca do uno, de modo que, se o verdadeiramente humano implicava relações de analogia entre todas as coisas e todos os seres, a realidade só poderia ser concebida em sua diversidade de formas e de relações.

No segundo número do segundo ano de Documents, já em 1930, então, Leiris (1930a, p. 57-70) dedicou um artigo à obra de Pablo Picasso. Para ele o principal mérito de Picasso não residia na ruptura com os cânones artísticos vigentes, mas, sim, no exemplo de alguém que se colocava no mesmo plano de todas as coisas, ao conferir o tratamento mais familiar possível a tudo que fosse humano. Nesse sentido, portanto, o pintor jamais poderia ser classificado como surrealista, como alguém "em revolta ou em fuga da realidade". De acordo com Leiris, Picasso fora considerado surrealista ao ser interpretado como um visionário - ou um "mage noir" - que pretendia substituir ao mundo de percepções cotidianas um mundo de essência superior.

A ambição de substituição do mundo existente por outro, moralmente superior, ou de construção de uma nova realidade, era clara no surrealismo, tal como elaborado por André Breton. Para Leiris, no entanto, Picasso não poderia ser considerado como um "inimigo do mundo". Ao contrário, deveria ser admirado por sua capacidade de exprimir todas as possibilidades da realidade, todas as suas ramificações imagináveis. As formas criadas pelo artista não se situariam nem acima nem abaixo das formas cotidianas, mas seriam tão verdadeiras quanto elas. Desse modo, jamais se poderia afirmar que a obra de Picasso fosse hostil à vida ou dela destacada. A verdadeira liberdade, segundo Leiris, não consistiria jamais em negar o real ou dele evadir-se, e sim, no seu reconhecimento necessário e na criação do novo a partir a do conhecimento e da valorização das coisas tais como eram, em seu valor próprio e em sua materialidade. Por isso Picasso seria um artista verdadeiramente livre: a cada nova combinação de formas, ele faria o espectador inserir-se mais humanamente na natureza, de forma mais concreta, mais densa e mais viva.

Ao comentar elogiosamente a exposição de Hans Arp na galeria Goemans, Leiris retomaria argumentos correlatos. Na obra de Arp, segundo Leiris (1929b, p. 340), aparecia

Oficina do Historiador, Porto Alegre, EDIPUCRS, v. 7, n. 2, jul./dez. 2014, p. 140-154. 
tudo o que estava situado entre "matéria bruta e pessoa, independentemente dos quatro reinos" e "ao mesmo tempo que ligado a tudo":

Hans Arp toma o universo e o transforma num metal ondulado, ele que conhece tão bem a carpintaria e tudo o que se pode tirar da matéria. Ele torce as formas e, sistematicamente, torna tudo semelhante a tudo, bagunçando classificações ilusórias e a escala mesma das coisas criadas. Ele se diverte com o mundo como um duende fugido de uma floresta e se coloca no meio das relações à maneira magnífica de um cachorro num jogo de boliche ${ }^{8}$ (LEIRIS, 1929b, p. 340).

No verbete "Métaphore", escrito, por sua vez, para o dicionário crítico no terceiro número de Documents, de junho de 1929, Leiris (1929c, p. 170) partia de sua definição clássica - aplicação do nome de um objeto a outro - para afirmar que nunca se poderia saber onde começava e onde terminava o jogo metafórico. Essa afirmação seria plausível, segundo ele, na medida em que a designação de um objeto pelo seu nome próprio, e não pelo figurado, necessitaria um conhecimento da essência desse objeto, o que seria impossível, já que os homens conheceriam "apenas os fenômenos e nunca as coisas em si”. Desse modo, era possível sustentar que não somente a linguagem, mas toda a vida intelectual, repousava sobre um jogo de transposições que se poderia qualificar de metafórico. De modo similar, todo conhecimento operaria por comparação: os objetos seriam, assim, ligados uns aos outros por relações de interdependência, sendo improvável determinar qual deles seria designado pelo nome próprio e qual deles seria metáfora de outro.

Leiris conferia à metáfora, portanto, uma força heurística, na medida em que novas combinações gerariam novos sentidos, nenhum deles afastando-se da realidade. Nesse sentido, as obras de Picasso e de Arp davam a ele a oportunidade de deparar-se com uma diversidade de formas, fazendo ver novas possibilidades humanas, novas possibilidades de relações entre homens e coisas.

Michel Leiris (1929d, p. 209-210) posicionava-se de modo muito similar em relação à obra do escultor Alberto Giacometti, sobre a qual escreveu no quarto número da revista, de

\footnotetext{
8 “'Hans Arp prend l'univers et le transforme en une tôle ondule, lui qui connait si bien la menuiserie et tout ce qu'on peut tirer de la matière. Il fait se gondoler les formes et, systématiquement, rendant tout presque semblable a tout, bouleverse les classifications illusoires et l'échelle même des choses crées. Il s'amuse avec le monde comme un lutin échappée d'une forêt et se comporte au milieu des relations à la manière magnifique d'un chien dans un jeu de quilles" (Tradução minha).
}

Oficina do Historiador, Porto Alegre, EDIPUCRS, v. 7, n. 2, jul./dez. 2014, p. 140-154. 
setembro de 1929. No mundo que se descortinava, segundo ele, ao mesmo tempo opressor e medíocre, em que grande parte das obras de arte não passava de "sinistra caricatura, fantasma, ou mesmo reflexo servil e falho da realidade", Picasso e Giacometti teriam conseguido escapar dessa atmosfera de tédio, fazendo com que o homem se reencontrasse sem medo, de modo alegre e bem humorado, com sua própria materialidade. Pode-se dizer que a obra de Giacometti representava aquilo que, para Leiris (1930b, p. 22), seria uma das "únicas tarefas válidas a que um homem poderia se propor": em suas palavras, "a abolição da insuportável dualidade estabelecida, graças à nossa moral corrente, entre corpo e alma, matéria e espírito". A abolição do dualismo metafísico cartesiano - fosse pelo erotismo, pelo misticismo ou pela poesia, por exemplo -, seria, assim, uma das formas possíveis do homem chegar a um estado de verdadeira comunhão consigo mesmo e com todas as coisas.

Criar laços de empatia - embora Leiris preferisse o vocabulário e o conjunto conceitual da mística, em geral - com o outro era, além de uma necessidade existencial, uma das possíveis belezas de um trabalho etnográfico bem feito. Nesse sentido, a força da obra de W. B Seabrook sobre o Vodu haitiano, por exemplo, residiria em sua "atitude humana". De acordo com Leiris (1929e, p. 344), Seabrook não cedia jamais ao "estúpido preconceito de raça" e colocava-se sempre "no mesmo plano dos nativos". Ademais, ele teria um desejo intenso que, segundo Leiris, “deveria ser o de todo homem”, de ultrapassar seus limites: "confundir-se com as bestas, com as plantas, com os minerais, afundar-se na grande sombra do 'de fora', mais real e mais viva do que ele". 9

O tema da assimilação ao "de fora" ou à "natureza" aparecia de forma clara no verbete "Métamorphose”, escrito para o mesmo número do periódico:

Eu lamento pelos homens que não sonharam, ao menos uma vez na vida, em mudar-se em qualquer um dos objetos que lhe entornam: mesa, cadeira,

\footnotetext{
9 “Voici enfin un occidental qui comprend (...) il se met de plain-pied avec les indigènes (...) admirateur passionné de toutes les mystiques, il se répugne à distinguer entre ces deux ordres de choses si voisins: mysticisme et érotisme. Ce qu'il voit avant tout, c'est le désir intense que devrait avoir tout homme de briser ses limites (...) se confondre avec les bêtes, les plantes, les minéraux, à s'abîmer dans la grande ombre du dehors, plus réelle et plus vivante que lui " (Tradução minha). Há, ainda, outro texto em Documents no qual Leiris escreveu especificamente sobre a disciplina etnográfica. Trata-se de um texto encomendado a ele pela direção da revista, um pouco antes de seu embarque na expedição Dakar-Djibouti (que foi a primeira grande expedição etnográfica francesa em seus territórios coloniais na África). Nesse texto, Leiris afirmava que a etnografia era uma "ciência magnífica" e "a mais humana", na medida em que nela todas as civilizações eram colocadas no mesmo plano e não se restringia ao estudo das mentalidades, interesses e técnicas dos homens brancos. Esse texto foi analisado por Fernanda Arêas Peixoto (2011, pp. 195-215).
}

Oficina do Historiador, Porto Alegre, EDIPUCRS, v. 7, n. 2, jul./dez. 2014, p. 140-154. 
animal, tronco de árvore, folha de papel. Eles não têm nenhum desejo de sair da própria pele, e esse contentamento calmo, que nenhuma curiosidade inquieta, é um sinal tangível dessa insuportável pretensão que é o apanágio mais claro na maior parte dos homens. Restar tranquilo na própria pele (...) é uma atitude contrária a toda paixão, e, consequentemente, a tudo o que existe de válido ${ }^{10}$ (LEIRIS, 1929f, p. 333).

Sair da própria pele, comungar-se consigo mesmo e com todas as coisas, investigar o mais profundo de si mesmo buscando o que poderia haver de comum com todos os outros: é possível afirmar que essa talvez tenha sido a maior ambição de Michel Leiris ao longo de grande parte de sua trajetória e que se materializaria em seu interesse pela etnografia, voltada tanto para si, quanto para o outro. Em famosa passagem de Carta do vidente, Rimbaud (cuja obra Leiris admirava intensamente), afirmava:

O primeiro estudo do homem que quer ser poeta é o conhecimento de si mesmo, inteiro; ele busca sua alma, ele a observa, tenta, aprende (instrui). (...) Eu digo que é preciso ser vidente, se fazer vidente. O poeta se faz vidente por um longo, imenso e pensado desregramento de todos os sentidos. Todas as formas de amor, de sofrimento, de loucura; ele busca a si mesmo, ele exaure em si mesmo todos os venenos, para então guardar apenas as quintessências (RIMBAUD, 1871).

De acordo com Charles Juliet (1988, p. 36-37), a escrita, para Leiris, era um modo de existir mais intensamente, uma operação mágica cujo substrato era o fortalecimento da consciência de si, por meio do registro dos "instantes de tangência entre si mesmo e o mundo". ${ }^{11}$ A experiência autoetnográfica seria assim, talvez, uma tentativa de chegar a um ponto obstruído pela "etnografia acadêmica".

Compreender o outro poderia ser também uma forma de compreender-se a si mesmo, não como "homem ocidental", mas como homem, simplesmente. O estabelecimento de um

\footnotetext{
10 “Je plains les hommes qui n'ont pas rêve, au moins une fois dans leur vie, de se changer en l'un quelconque des divers objets qui les entourent : table, chaise, animal, tronc d'arbre, feuille de papier... Ils n'ont aucun désir de sortir de leur peau, et ce contentement paisible, troublé par nulle curiosité, est un signe tangible de cette insupportable suffisance qui est l'apanage le plus clair de la plupart des hommes. Rester tranquille dans sa peau, (...) est une attitude contraire à toute passion, par conséquent à tout ce qu'existe de valable " (Tradução minha).

${ }^{11}$ A frase entre aspas foi utilizada por Leiris em O espelho da tauromaquia (LEIRIS, 2001 [1938], p. 75).
}

Oficina do Historiador, Porto Alegre, EDIPUCRS, v. 7, n. 2, jul./dez. 2014, p. 140-154. 
estado de comunhão com todas coisas se daria, assim, a partir das relações engendradas entre os homens:

\begin{abstract}
Aquilo que nos dá a única possibilidade de nos religarmos a ela [à natureza], é a existência de uma natureza humana, ou seja, a existência de outras criaturas humanas que exercem a função de mediadoras, graças ao fato de que elas, ao mesmo tempo, participam da natureza - porque nos são exteriores como ela - e participam de nós mesmos (porque sua constituição é parecida com a nossa) $)^{12}$ (LEIRIS, 1930c, p. 261).
\end{abstract}

No que concernia à abolição da dualidade entre matéria e espírito, propriamente, podese voltar, mais uma vez, ao texto "À propos du musée des sorciers": os sistemas mágicos de pensamento, representados especialmente pelo totemismo primitivo e, nas civilizações ocidentais, pelo misticismo ou pelas ciências ocultas, estariam de acordo com alguns dos traços mais instintivos do homem, como a busca pelo maravilhoso e pelo absoluto, ou pelo uno. O maravilhoso, como explicava Leiris (1929g, p. 109) nesse artigo, não se encontrava nem na natureza nem além da natureza, mas no interior do próprio homem, num território que escapava, em suas palavras, "às forças atrozes de causas, editos racionais e potências pragmáticas". Em um mundo sem Deus e sem dualismos metafísicos, porém, esse "interior" ao qual tantas vezes se referia, poderia ser representado tanto por forças inconscientes ou instintivas, quanto pela própria materialidade do corpo.

Essa perspectiva também ficava clara, por exemplo, no artigo intitulado "L'homme et son intérieur", escrito para o quinto número de Documents, em 1930. Leiris (1930c, p. 261266) afirmava, então, que de todas as representações plásticas a do corpo humano era a mais impressionante. Não se tratava, no entanto, "do nu convencional da pintura oficial", muito menos dos nus de intenções naturalistas, nos quais apenas a estrutura aparente dos corpos era estudada. Essas imagens seriam desumanizadas, na medida em que não evocavam, em seus termos, "nem mesmo a sombra da visão da realidade de um corpo" e excluíam tudo aquilo

12 “Ce qui nous donne la possibilité de nous relier à elle, c'est l'existence d'une nature humaine, c'est-à-dire, l'existence de créatures humaines autres que nous, qui font alors fonction de médiatrices, grâce au fait que d'un côté elles participent de la nature (puisqu'elles nous sont extérieures comme elle) en même temps que d'un autre côté elles participent de nous-mêmes (puisque leur constitution est à peu près semblable à notre constitution même" (Tradução minha).

Oficina do Historiador, Porto Alegre, EDIPUCRS, v. 7, n. 2, jul./dez. 2014, p. 140-154. 
que pudesse fornecer as ligações reais e sensíveis entre os seres humanos e o universo. Marcas e órgãos do corpo humano seriam, então, de acordo com ele, "signo vivo" dessa aliança que a natureza consentira, "selos mágicos" que consagrariam esse pacto suposto.

Nesse sentido, por exemplo, tanto as tatuagens ritualísticas dos povos primitivos - que os colocavam em relação com todas as partes do universo - quanto as tatuagens do homem civilizado, "amante de sensações raras", seriam apenas algumas das diversas formas de ceder à necessidade de sentir-se mais humano. Era possível afirmar exatamente o mesmo em relação às práticas sadomasoquistas: as trocas e relações mais profundas e brutas entre os corpos não seriam mais do que meios de intensificação da consciência humana - humanidade que, segundo Leiris, nada teria a ver com felicidade, muito menos com bondade: mesmo as visões mais atrozes e os prazeres mais cruéis seriam legítimos, desde que contribuíssem para o aprofundamento do humano (LEIRIS, 1930c, p. 261-266).

Desse modo, todas as possibilidades do real, para Leiris, implicavam, necessariamente, todas as possibilidades do humano, e inversamente. Ao longo de toda a sua vida como escritor, crítico de arte e etnólogo, Leiris procuraria entender a realidade, a si mesmo e o outro, num sistema analógico de semelhanças legíveis, procurando fazer-se vidente.

Colocado face a face com a crueza de suas funções orgânicas, com a materialidade de sua existência, em suas relações reais, as mais humanas possíveis, o homem poderia, talvez, livrar-se da "atmosfera fria, morta e vã" engendrada pela civilização industrial na qual se encontrava, e que o transformava em cadáver. Abolir hierarquias, "ampliar o horizonte até uma medida humana" era, sobretudo, reconhecer o caráter simultaneamente baixo e elevado de sua própria existência material e corporal.

Se for aceita a sua própria sugestão de que todo conhecimento opera metaforicamente, torna-se possível pensar que cada um dos escritos de Leiris foi concebido analogicamente em relação a Documents, em seu conjunto. A revista foi, para ele, um profícuo laboratório para o olho, olho que faz ver, que tudo quer ver e que procura enxergar as coisas tais como são, ou seja, desordenadas, inacabadas, sujas, violentas, diversas, impossíveis e profundamente humanas. Os fatos materiais, os documentos humanos, objetos e acontecimentos do cotidiano poderiam despertar uma nova ideia - não uma ideia superior, transcendental, mas uma ideia fincada na realidade, em suas mais variadas formas. As potencialidades do contágio de uma forma por outra, a capacidade de entender o corpo humano como uma materialidade aberta à

Oficina do Historiador, Porto Alegre, EDIPUCRS, v. 7, n. 2, jul./dez. 2014, p. 140-154. 
transformação e metamorfose (ou fusão), a partir do contato seriam, sem dúvida, ideias caras a Leiris ao longo de sua vida e em suas reflexões posteriores como etnólogo.

Nesse sentido, a amizade com Bataille e os debates travados entre os dois marcariam, sem dúvida, as reflexões de Leiris. Porém, tanto pelos textos escritos para a revista, quanto em passagens (mais explícitas) em seu diário íntimo, era possível perceber as diferenças entre eles. No diário, Leiris (1992a, p. 147; 171) afirmou que considerava Bataille "muito esteticamente materialista" e que seu dualismo era de "caráter maniqueísta". Ele mesmo, por sua vez, não fazia "nenhuma ideia mística da contradição". ${ }^{13}$ Bataille, por outro lado, muitas vezes considerava Leiris "idealista", como ele assegurava no diário: "lapso de Bataille, ontem, em uma discussão no curso da qual me chamou de 'idealista' e de 'kantiano': 'aperitivo categórico""14 (LEIRIS, 1992a, p. 388). O tout autre de Bataille convertia-se, sempre, no si mesmo, para Leiris, a partir da ideia de "homem como microcosmo", cara às vertentes filosóficas do chamado Renascimento que operavam em regime analógico e de correspondência. Leiris produziria, ao longo da vida, uma série de textos e reflexões sobre temas etnográficos em que enfatizaria as semelhanças entre os homens, em detrimento das diferenças: "não é humilhante para nós, que nos dizemos civilizados e pretendidos à cultura, sermos sempre antes sensíveis às diferenças e, dominados por um choque de primeira vista (...), nos apegarmos mais a elas do que às semelhanças?” (LEIRIS, 1992b, p. 53-54).

\section{REFERÊNCIAS BIBLIOGRÁFICAS}

BATAILLE, Georges. Matérialisme. In: Euvres complètes, t. I. Paris: Gallimard, 1970

DIDI-HUBERMAN, Georges. La ressemblance informe ou Le gai savoir visuel selon Georges Bataille. Paris: Macula, 1995.

DUARTE, Luiz Fernando Dias. "A pulsão romântica e as ciências humanas no Ocidente. In: Revista brasileira de ciências sociais (RBCS), vol. 19, número 55, Junho, 2014. Disponível em <http://www.scielo.br/pdf/rbcsoc/v19n55/a01v1955.pdf>. Acesso em 20 de maio de 2014

O paradoxo de Bergson. Diferença e Holismo na antropologia do Ocidente. In: Mana, vol. 18, número 3, dezembro, 2012. Disponível em:

\footnotetext{
13“ En tout cas, je ne me fais plus aucune idée mystique de la contradiction ”. (...) “Je situe d'un mot quelqu'un de mes amis présents : (...) Bataille, trop esthétiquement matérialiste”. (...) “Vu Bataille, qui me confirme que sa conception matérialiste est d'ordre manichéiste " (Tradução minha)

14“'Lapsus de Bataille, hier, dans une discussion au cours de laquelle il me traita 'd'idéaliste' et de 'kantien' : 'l'apéritif catégorique'" (Tradução minha).
}

Oficina do Historiador, Porto Alegre, EDIPUCRS, v. 7, n. 2, jul./dez. 2014, p. 140-154. 
<http://www.scielo.br/scielo.php?pid=S0104-93132012000300001\&script=sci_arttext $>$.

Acesso em: 20 mai. 2014

HOLLIER, Denis. The use-value of the impossible. In: October. Vol. 60, 1992. Disponível em: <http://rae.com.pt/TC/Hollier\%20use\%20value\%20of\%20documents.pdf $>$. Acesso em: 20 mai. 2014

JULIET, Charles. Pour Michel Leiris. Paris: Fourbis, 1988

LAGROU, Els. A arte do outro no surrealismo e hoje. In: Horizontes Antropológicos. Ano 14, número 29, Porto Alegre, jan/jun 2008. Disponível em: <http://www.scielo.br/pdf/ha/v14n29/a09v14n29.pdf>._Acesso em: 20 mai. 2014

LEIRIS, Michel. Alberto Giacometti. In: Documents: archéologie, beaux-arts, ethnographie, variétés; n. 4, ano 1, setembro de 1929d

À propos du musée des sorciers. In : Documents : doctrines, archéologie, beauxarts, ethnographie, n. 2, ano 1, maio de 1929g

LEIRIS, Michel. Exposition Hans Arp. In : Documents : archéologie, beaux-arts, ethnographie, variétés, n. 6, 1929b

Le "caput mortuum" ou la femme de l'alchimiste. In : Documents : archéologie, beaux-arts, ethnographie, variétés, n. 8, ano 2, 1930b

L'homme et son intérieur. In : Documents : archéologie, beaux-arts, ethnographie, variétés, n. 5 ano 2, 1930c

variétés, n. 6, 1929e

L'ile Magique. In : Documents : archéologie, beaux-arts, ethnographie,

Métamorphose/hors de soi. In: Documents : archéologie, beaux-arts, ethnographie, variétés, n. 6, 1929f

Méthaphore. In : Documents : doctrines, archéologie, beaux-arts, ethnographie, n. 3, ano 1 , junho de $1929 \mathrm{c}$

Notes sur deux figures microcosmiques des XIV e XV siècles. In : Documents : doctrines, archéologie, beaux-arts, ethnographie ; n. 1, ano 1, abril de 1929a

Toiles récentes de Picasso ». In : Documents : archéologie, beaux-arts, ethnographie, variétés, $n$. 2, ano 2, 1930a

From Bataille the impossible to the impossible Documents. In: Correspondence: Georges Bataille, Michel Leiris. NY: Seagull Books, 2008

Journal (1922-1989). Paris : Galimmard, 1992a

Oficina do Historiador, Porto Alegre, EDIPUCRS, v. 7, n. 2, jul./dez. 2014, p. 140-154. 
L'Abyssinie intime. In: Mer et autre mer, n. 1, juin 1935, pp. 43-47. Reprisado em LEIRIS, Michel. Zébrage. Paris: Gallimard, 1992b

. O espelho da tauromaquia. São Paulo: Cosac\&Naify, 2001

MORAES, Marcelo Jacques. Georges Bataille e as formações do abjeto. In: Outras travessias, número 4, Santa Catarina, 2005

MORAES, Eliane Robert. O corpo impossível. São Paulo: Iluminuras, 2010

PEIXOTO, Fernanda Arêas. "A viagem como vocação: antropologia e literatura na obra de Michel Leiris”. In: LEIRIS, Michel. África fantasma. São Paulo: Cosac\&Naify, 2007

. "O olho do etnógrafo". In: Sociologia\&Antropologia, vol. 0I, número 2, 2011.

Disponível em: <http://revistappgsa.ifcs.ufrj.br/pdfs/ano1v2_artigo_fernanda-areaspeixoto.pdf>._Acesso em: 20 mai de 2014

PRICE, Sally. Arte primitiva em centros civilizados. Rio de Janeiro: UFRJ, 2000.

RIMBAUD, Arthur. Carta do Vidente. Disponível em:

$<$ http://www.salamalandro.redezero.org/wp-content/uploads/2007/07/Rimbaud-A-carta-dovidente-Lettre-a\%CC\%80-Paul-De\%CC\%81meny.pdf>. Acesso em: 20 mai. 2014

THEOPHILO, Gabriela. A revista de etnografia Documents e seu projeto documental-realista (França, 1929-1930). In: Anais do Sexto seminário brasileiro de história da historiografia O giro linguístico e a historiografia: balanços e perspectivas. Ouro Preto: EdUFOP, 2012. Disponível em <http://www.seminariodehistoria.ufop.br/ocs/index.php/snhh/2012/paper/viewFile/1002/716. Acesso em: 16 jul. 2014.

ARTIGO ENVIADO EM: 20/05/2014 ACEITO PARA PUBLICAÇÃO EM: 16/07/2014 